\title{
Surgical Site Infections and Antimicrobial Resistance Pattern
}

Raskin Chaudhary, ${ }^{1}$ Shrawan Kumar Thapa, ${ }^{2}$ Jid Chani Rana, ${ }^{3}$ Pradeep Kumar Shah ${ }^{4}$

'Department of Microbiology, St. Xavier's College, Kathmandu, ${ }^{2}$ Orthopaedic Department, Bharatpur Hospital, Chitwan, '3aboratory Department, Bharatpur Hospital, Chitwan, ${ }^{4}$ Department of Microbiology,

Tri- Chandra College, Kathmandu, Nepal.

\section{ABSTRACT}

\begin{abstract}
Background: Post-operative surgical site infections (SSIs) are among the leading cause of morbidity and increased medical expense. The aim of this study is to isolate identify and study antimicrobial susceptibility pattern of microorganism from surgical wound of admitted patients.

Methods: This retrospective study was carried at the Microbiology Laboratory of Bharatpur hospital, Nepal, from May 2015 to October 2015. The pus samples were cultured and antibiotic susceptibility determined in vitro by Kirby Bauer's disc diffusion method following clinical and Laboratory Standards Institute (CLSI) 2014 recommendation.

Results: Of the total 250 samples, 194 (77.6\%) showed bacterial growth. Staphylococcus aureus was 47.4\% and Escherichia coli $20.60 \%$. Of 194 isolates $39.2 \%$ were multi drug resistant. Amikacin was sensitive in $93.1 \%$ of Gram positive isolates and $81.8 \%$ of gram negative isolates.

Conclusions: Bacterial growth is common in surgical site. Staphylococcus aureus and Escherichia coli were multidrug resistant. Grampositive and gram negative isolates were commonly sensitive to Amikacin.
\end{abstract}

Keywords: Antibiotic susceptibility; multidrug resistant bacteria; surgical site infections; Staphylococcus aureus.

\section{INTRODUCTION}

According to Center for Disease Control and Prevention $(C D C)$, surgical site infections (SSIs) are defined as infection that occurs at incision site within 30 days after surgery. ${ }^{1}$ Post operative surgical site infection is the leading nosocomial cause of morbidity and increase in medical expense. ${ }^{2}$

Wound infection remains an ongoing problem. Control measures against the common isolates and wound care may minimize infection. ${ }^{3}$ Rapidly emerging nosocomial pathogens and multi drug resistance necessitates the periodic review of isolation patterns and sensitivity in surgical practice.

This study was conducted to generate data that would help clinicians as guideline in early diagnosis and selection of correct empirical antimicrobial therapy pathogens causing SSI.

\section{METHODS}

This hospital based cross-sectional study was carried from May 2015 to October 2015 in the microbiology laboratory of Bharatpur Hospital, Chitwan, Nepal. A total of 250 pus samples including wound swab on a sterile cotton swab or aspirated pus in syringe from the surgical wounds were collected from the patient after obtaining written informed consent from the patient and processed following the standard laboratory techniques. Approval for this study was obtained from the Nepal Health Research Council (NHRC) Ethical Review Board on $30^{\text {th }}$ August 2015.

The sample was inoculated on Sheep blood agar, MacConkey agar and Mannitol salt agar; and the plates were incubated at $37^{\circ} \mathrm{C}$ for 24 hours aerobically. The identification of the isolates was done based on a standard microbiological technique microscopic examination, colony morphology and biochemical tests such as indole test, MR-VP test, citrate utilization test, TSIA test urease test, dry spot agglutination test for Staphylococcus, API 20E and API 20NE. ${ }^{4}$ All the isolates were tested for antimicrobial susceptibility by modified Kirby-Bauer's disc diffusion technique on Muller Hinton No.2 agar using antibiotics as per CLSI 2014 guidelines. ${ }^{5}$ Standard strains used for Quality Control of the procedure were Escherichia coli (ATCC 25922), and Staphylococcus aureus (ATCC 25923). Statistical analysis was performed using SPSS software version16.0 for determining the association of incidence of SSI in patients of different age groups and gender.

Correspondence: Raskin Chaudhray, St. Xavier's College, Maitighar Kathmandu, Nepal. Email:raskinchaudhary@gmail.com, Phone: +9779845062695. 


\section{RESULTS}

Out of 250 samples (114 swabs and 136 aspirates), 194 samples (180 single isolates, 13 two or double isolates and 1 three isolates) were culture positive (Figure 1). Infection rate in female was found to be $78 \%$ while in males was $77.3 \%$ and similarly infection rate in the age group $15-30$ years was $30.9 \%$ and in the age group $<15$ years was $28.86 \%$.

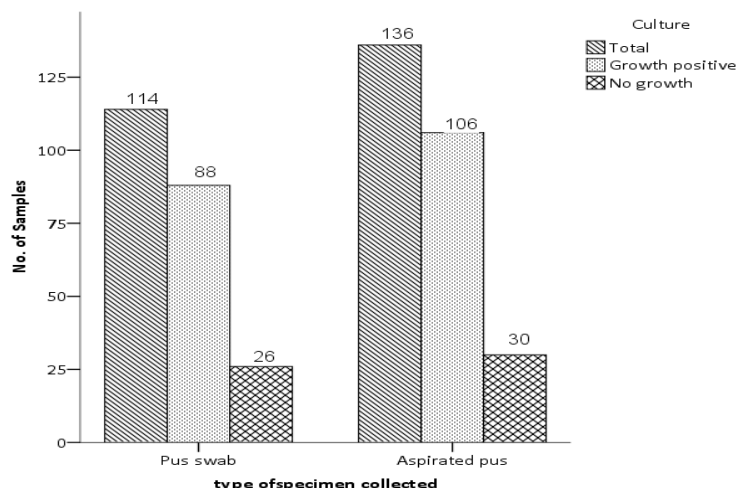

Figure 1. Pattern of growth in different types of sample.

Out of 250 samples, 202 (80.8\%) were collected from the surgical ward, followed by $28(11.2 \%)$ from the orthopedic ward, $12(4.8 \%)$ from the gynae ward, $4(1.6 \%)$ from medical ward and $3(1.2 \%)$ from ICU of the hospital. The least number of sample, $1(0.4 \%)$ was collected from ENT. Out of 194 positive samples, the highest number of positive samples were from surgical ward $161(83 \%)$, of which $58.4 \%$ were Gram positive isolates and $41.6 \%$ were Gram negative isolates, followed by orthopedic ward 18 (9.3\%). Staphylococcus aureus was the commonest isolate (47.4\%) followed by Escherichia coli (20.60\%), Coagulase negative staphylococci (CoNS (5.7\%), Acinetobacter spp. (5.2\%), Klebsiella spp. (5.15\%), Proteus mirabilis (3.1\%), Pseudomonas spp. (2.1\%), Aeromonas hydrophillia (1.5\%), Enterococcus spp. (2.6\%), Streptococcus spp. (1.5\%) and Morganella morgani (1\%). Other organisms (Burkholderia spp., Erwinia spp, Aerococcus spp, Corynebacterium spp, Enterobacter spp.) constituted less than 1\% each of total isolates.

The most effective antibiotic for the Gram positive isolates was Amikacin (93.1\%) followed by Chloramphenicol (92.6), Piperacillin/Tazobactam (86.2\%), Clindamycin (81.7\%) and Gentamicin (79.6\%) (Table 1).

Amikacin $(81.8 \%)$ and Imipenem $(81.8 \%)$ was found to be the drug of choice for gram negative bacterial wound isolates followed by Gentamicin (73.0\%), Piperacillin/ Tazobactam (72.2\%) and Meropenem (60.7\%) (Table 2). The most effective drugs against Staphylococcus aureus was Chloramphenicol (97.6\%), followed by Amikacin (97.3\%), Piperacillin/Tazobactam (88.2\%), Clindamycin $(87.0 \%)$ and Gentamicin (82.0\%).

The Multidrug resistant (MDR) isolates were Staphylococcus aureus 35 (38.0\%), Escherichia coli 16 (40.0\%), Pseudomonas aeruginosa 1 (25.0\%), Klebsiella

Table 1. Antimicrobial susceptibility pattern of gram positive bacteria.

\begin{tabular}{|c|c|c|c|c|c|c|c|}
\hline \multirow{2}{*}{ Antibiotics used } & Susceptible & & Intermediate & & Resistant & & \multirow{2}{*}{ Total } \\
\hline & No. & $\%$ & No. & $\%$ & No. & $\%$ & \\
\hline Imipenem (IPM10mcg) & 31 & $93.9 \%$ & - & - & 2 & $6.1 \%$ & 33 \\
\hline Tetracycline (TE30mcg) & 31 & $93.9 \%$ & 1 & $3.0 \%$ & 1 & $3.0 \%$ & 33 \\
\hline Meropenem (MRP10mcg) & 41 & $93.2 \%$ & 1 & $2.3 \%$ & 2 & $4.5 \%$ & 44 \\
\hline Amikacin (AK30mcg) & 81 & $93.1 \%$ & 1 & $1.1 \%$ & 5 & $5.7 \%$ & 87 \\
\hline Chloramphenicol (C30mcg) & 50 & $92.6 \%$ & - & - & 4 & $7.4 \%$ & 54 \\
\hline $\begin{array}{l}\text { Piperacillin/Tazobactam } \\
\text { (PIT100/10mcg) }\end{array}$ & 50 & $86.2 \%$ & 1 & $1.7 \%$ & 7 & $12.1 \%$ & 58 \\
\hline Azithromycin (ÁZM15mcg) & 10 & $83.3 \%$ & - & - & 2 & $16.7 \%$ & 12 \\
\hline Clindamycin (CD2mcg) & 89 & $81.7 \%$ & 2 & $1.8 \%$ & 18 & $16.5 \%$ & 109 \\
\hline Gentamicin (GEN10mcg) & 82 & $79.6 \%$ & 5 & $4.9 \%$ & 16 & $15.5 \%$ & 103 \\
\hline Ofloxacin (OF5mcg) & 11 & $73.3 \%$ & 1 & $6.7 \%$ & 3 & $20.0 \%$ & 15 \\
\hline Erythromycin (E15ncg) & 13 & $59.1 \%$ & 2 & $9.1 \%$ & 7 & $31.8 \%$ & 22 \\
\hline Cefotaxime (CTX30mcg) & 23 & $57.5 \%$ & 14 & $35.0 \%$ & 3 & $7.5 \%$ & 40 \\
\hline $\begin{array}{l}\text { Trimethoprim/Sulphamethoxazole } \\
\text { (COT1.25/23.75mcg) }\end{array}$ & 41 & $55.4 \%$ & 6 & $8.1 \%$ & 27 & $36.5 \%$ & 74 \\
\hline Ceftriaxone (CTR30mcg) & 31 & $54.4 \%$ & 14 & $24.6 \%$ & 12 & $21.1 \%$ & 57 \\
\hline Ciprofloxacin (CIP5mcg) & 39 & $42.4 \%$ & 35 & $38.0 \%$ & 18 & $19.6 \%$ & 92 \\
\hline
\end{tabular}


Surgical Site Infections and Antimicrobial Resistance Pattern

\begin{tabular}{|lrrrrrrr}
\hline Trimethoprim (TR5mcg) & 13 & $40.6 \%$ & 2 & $6.2 \%$ & 17 & $53.1 \%$ & 32 \\
\hline Gatifloxacin (GAT5mcg) & 24 & $30.8 \%$ & 3 & $3.8 \%$ & 51 & $65.4 \%$ & 78 \\
\hline Ampicillin (AMP10mcg) & 10 & $13.9 \%$ & 1 & $1.4 \%$ & 61 & $84.7 \%$ & 72 \\
Ceftazidime (CAZ30mcg) & 2 & $13.3 \%$ & 2 & $13.3 \%$ & 11 & $73.3 \%$ & 15 \\
\hline Penicillin-G (P10units) & 5 & $11.6 \%$ & - & - & 38 & $88.4 \%$ & 43
\end{tabular}

Table 2. Antimicrobial susceptibility pattern of gram negative bacteria.

\begin{tabular}{|c|c|c|c|c|c|c|c|c|}
\hline \multirow{2}{*}{ Antibiotics used } & \multirow{2}{*}{$\begin{array}{l}\text { Susceptible } \\
\text { No. }\end{array}$} & \multicolumn{3}{|c|}{ Intermediate } & \multicolumn{2}{|c|}{ Resistant } & \multirow{2}{*}{\multicolumn{2}{|c|}{ Total }} \\
\hline & & $\%$ & No. & $\%$ & No. & $\%$ & & \\
\hline Amikacin (AK30mcg) & 54 & $81.8 \%$ & 2 & $3.0 \%$ & 10 & $15.2 \%$ & & 66 \\
\hline Imipenem (IPM10mcg) & 45 & $81.8 \%$ & 5 & $9.1 \%$ & 5 & $9.1 \%$ & & 55 \\
\hline Chloramphenicol (C30mcg) & 15 & $78.9 \%$ & - & - & 4 & $21.1 \%$ & & 19 \\
\hline $\begin{array}{l}\text { Cefoperazone/sulbactam } \\
\text { (CFS50/50mcg) }\end{array}$ & 6 & $75.0 \%$ & - & - & 2 & $25.0 \%$ & & 8 \\
\hline Gentamicin (GEN10mcg) & 54 & $73.0 \%$ & 2 & $2.7 \%$ & 18 & $24.3 \%$ & & 74 \\
\hline $\begin{array}{l}\text { Piperacillin/Tazobactam } \\
\text { (PIT100/10mcg) }\end{array}$ & 57 & $72.2 \%$ & 4 & $5.1 \%$ & 18 & $22.8 \%$ & & 79 \\
\hline Meropenem (MRP10mcg) & 17 & $60.7 \%$ & 1 & $3.6 \%$ & 10 & $35.7 \%$ & & 28 \\
\hline Ciprofloxacin (CIP5mcg) & 38 & $52.0 \%$ & 7 & $9.6 \%$ & 28 & $38.4 \%$ & & 73 \\
\hline Gatifloxacin (GAT5mcg) & 25 & $48.1 \%$ & 3 & $5.8 \%$ & 24 & $46.2 \%$ & & 52 \\
\hline Ceftriaxone (CTR30mcg) & 31 & $45.6 \%$ & 5 & $7.4 \%$ & 32 & $47.1 \%$ & & 68 \\
\hline Ceftazidime (CAZ30mcg) & 23 & $43.4 \%$ & 3 & $5.7 \%$ & 27 & $50.9 \%$ & & 53 \\
\hline Tetracycline (TE30mcg) & 8 & $40.0 \%$ & - & - & 12 & $60.0 \%$ & & 20 \\
\hline Cefotaxime (СTX30mcg) & 16 & $34.0 \%$ & 6 & $12.8 \%$ & 25 & $53.2 \%$ & & 47 \\
\hline $\begin{array}{l}\text { Trimethoprim/Sulphamethoxazole } \\
\text { (COT1.25/23.75mcg) }\end{array}$ & 17 & $32.7 \%$ & 2 & $3.8 \%$ & 33 & $63.5 \%$ & & 52 \\
\hline $\begin{array}{l}\text { Amoxycillin/Clavulinic Acid } \\
\text { (AMC20/10mcg) }\end{array}$ & 18 & $26.9 \%$ & 7 & $10.4 \%$ & 42 & $62.7 \%$ & & 67 \\
\hline Ampicillin (AMP10mcg) & 1 & $5.3 \%$ & - & - & 18 & $94.7 \%$ & & 19 \\
\hline
\end{tabular}

spp. 2 (20.0\%), Acinetobacter complex 7 (70\%), Proteus mirabilis 1 (16.7\%), Coagulase negative staphylococci (CoNS) 3(27.3\%), Enterococcus spp. 4(80\%), Streptococcus spp. $1(33.3 \%)$ and others $6(66.7 \%)$.

\section{DISCUSSION}

In the present study $77.6 \%$ of samples showed significant bacterial growth and $7.2 \%$ were with multiple organisms (polymicrobial) which agreed with similar study by Naik et al. done in Mangalore, India. ${ }^{6}$ The growth rate was however, higher than that reported by Acharya et al. ${ }^{7}$ and Amatya et al. ${ }^{8}$ Contamination from the external environment and poor hospital hygiene may be the possible reason for higher rate of surgical site infection. ${ }^{6}$

Infection rate in female (78\%) was found to be higher than in males (77.3\%); and similarly, infection rate in the age group $15-30$ years (30.9\%) was higher than other age groups. However, the prevalence of wound infections was not significantly affected by age and gender $(p>0.05)$ which is consistent with other studies conducted in Nepal.
Among the isolates in this study, Gram positive organisms constituted 58.4\% and Gram negative bacilli were $41.6 \%$ which agreed with study done by Acharya et al. ${ }^{7}$ This result was different from Banjara et al., according to which $27 \%$ were Gram positive and $73 \%$ were Gram negative bacteria. ${ }^{9}$ The possible reason for variation in the studies could be attributed to differences in the populations investigated; diversity of surgical procedures performed on the study participants, as well as timing of specimen collections. ${ }^{8}$

Many studies have reported Staphylococcus aureus as the commonest isolate from the wound infections. ${ }^{10,11}$ In the present study, predominance of Staphylococcus aureus constituting $47.4 \%$ of all isolates in wound infections was similar with reports from other studies. In our study other organisms isolated were Escherichia coli (20.60\%), Coagulase negative staphylococci (CoNS (5.7\%), Acinetobacter spp. (5.2 \%), Klebsiella spp. (5.15\%), Proteus mirabilis (3.1\%), Pseudomonas spp. (2.1\%), Aeromonas hydrophillia (1.5\%), Enterococcus spp. (2.6\%), Streptococcus spp. (1.5\%) and Morganella morgani (1\%). 
The most effective antibiotic for the Gram positive isolates in our study was Amikacin (93.1\%) followed by Chloramphenicol (92.6\%), Piperacillin/Tazobactam (86.2\%), Clindamycin (81.7\%) and Gentamicin (79.6\%). Amikacin (81.8\%) and Imipenem (81.8\%) was found to be the drug of choice for gram negative bacterial wound isolates followed by Gentamicin (73.0\%), Piperacillin/ Tazobactam (72.2\%) and Meropenem (60.7\%). This result was different from the study of Kumari (2008), in which the Gram negative isolates were sensitive to Imipenem (97.62\%), Amikacin (82.14\%) and Gentamicin (52.38\%), while least effective was Amoxyclav (14.29\%) and Ceftriaxone (23.81\%). ${ }^{12}$

The microorganisms resistant to at least one antibiotic of three or more than three different classes of antibiotics were considered Multidrug resistant (MDR). In the current study, $39.2 \%$ of the isolates were found to be MDR. The result of our study agrees with the similar study carried by Banjara et al. in which $47.2 \%$ isolates was MDR isolates. ${ }^{9}$ The multi drug resistant bacteria are important cause of nosocomial infection and infection associated with such microorganism pose serious threat to vulnerable patients who are immunocompromised. Hence, infectious disease care centers and hospitals make frequent use of antimicrobial agents, resulting in increasing cases of resistance and multi drug resistance. However, in a similar study conducted by Raza et al., $66.67 \%$ of the bacterial isolates showed multi drug resistant. ${ }^{13}$

\section{CONCLUSIONS}

The main culprit for wound infection was the trivial organisms like S. aureus, E. coli, P. aeruginosa, Klebsiella spp., etc Gram positive bacteria were found to be more predominant in the postoperative wound samples compared to the Gram negative organisms. Staphylococcus aureus, Eschericha coli were multidrug resistant. Gram positive and gram negative isolates were commonly sensitive to amikacin.

\section{REFERENCES}

1. CDC public health's focus surveillance, prevention and control of nosocomial infection. MMWR. 1992;(41):7837.[PubMed]

2. Zafar A, Anwal N and Hasan E. Bacteriology of infected wound- a study conducted at childrens hospital Lahore Biomedica. 2008;24:71-4.

3. Bowler PG, Dueren BI and Armstrong DG. Wound microbiology and associated approaches to wound management. Clin Microbial Rev.2001; 14(2):244-69. [Link]

4. Cheesbrough M. District Laboratory Practice In Tropical Countries. Part $22^{\text {nd }}$ ed. Cambridge University Press 2000: ISBN-13 978-0-521-67631-1[Link]

5. CLSI Performance Standards for Antimicrobial Susceptibility Testing; Twenty-Fourth Informational Supplement. Wayne, PA: Clinical and Laboratory Standards Institute 2014; 34(1) CLSI document M100-S24.

6. Naik G, Deshpande SR. A Study on surgical site infection caused by staphylococcus aureus with a special search for methicillin resistant isolates. J Clin Diagn Res. 2011; 5 (3):502-8. Link

7. Acharya J, Mishra SK, Katel HP, Rijal P, Pokherel BM. Bacteriology of wound infection among patients attending Tribhuvan University, Teaching hospital, Kathmandu Nepal. JJournal of Nepal Association for Medical Laboratory Sciences. 2008; 9(1):76-80.

8. Amatya J, Rijal M, Baidya R. Bacteriological study of the post operative wound sample and antibiotic susceptibility pattern of isolates in B \& B hospital. JSM Microbiology. 2015; 3(1):10-9.

9. Banjara MR, Sharma AP, Joshi AB, Tuladhar N, Ghimire P, Bhatta DR. Surgical wound infection and their antibiogram in patients of Tribhuvan University teaching hospital. J Nepal Health Res Counc. 2003; 1:41-5.

10. Lilani SP, Jangale N, Chowdhary A, Daver GB. Surgical site infection in clean and clean-contaminated cases. Indian J Med Microbiol. 2005; 23:249-52. Available from: http:// www.ijmm.org/text.asp?[Link]

11. Mohantay S, Kapil A, Dhawan B, Das BK. Bacteriological and antimicrobial susceptibility profile of soft tissue infections from Northern India. Indian J Med Sci. 2004; 58: 10-5. [Link]

12. Kumari K. Pattern of bacterial isolates and antibiogram from open wound infection among the indoor patients of Bir Hospital. A Dissertation submitted to the Central Department of Microbiology, Tribhuvan University, Kathmandu, Nepal. 2008.

13. Raza MS, Chander A, Ranabhat A. Antimicrobial susceptibility patterns of the bacterial isolates in postoperative wound infections in a tertiary care hospital, Kathmandu, Nepal. Open J Med Microbiol. 2013; 3: 15963. 